\title{
ADENYLATE CYCLASE ACTIVITY IN THE FETAL AND THE EARLY POSTNATAL INNER EAR OF THE MOUSE
}

\author{
M. ANNIKO ${ }^{1,2}$, M.-L. SPANGBERG ${ }^{2}$ and J. SCHACHT ${ }^{2,3}$ \\ ${ }^{1}$ Department of Otolaryngology, Karolinska sjukhuset, S-104 01 Stockholm, ${ }^{2}$ King Gustaf V \\ Research Institute, Karolinska Institutet, S.104 01 Stockholm, Sweden, and ${ }^{3}$ Kresge Hearing \\ Research Institute, University of Michigan, Ann Arbor, MI 48109, U.S.A.
}

(Received 10 September 1980; accepted 23 September 1980)

The adenylate cyclase activity was analyzed in fetal, early postnatal and adult inner ears of the CBA/CBA mouse and also in approximately one month old inner ears from Shaker -1 and Shaker -2 mice. A comparison was made with the maturation of potassium levels in endolymph as investigated with the X-ray energy dispersive technique.

Adenylate cyclase activity in the developing normal inner ear shows two significant periods of increases: from the 16 th to the 19 th gestational day in both the cochlear and vestibular parts of the labyrinth, and from birth to day 6 after birth in the lateral wall tissues of the scala media. During the first period the anatomical boundaries of the secretory epithelia are developing. The postnatal rise in adenylate cyclase activity correlates with the morphological maturation of stria vascularis at the cellular and subcellular levels and the rise in potassium content of endolymph. The rise of enzyme activity in the cochlea during the maturation of endolymph supports a link between adenylate cyclase and the control of inner ear fluids. Adenylate cyclase activity in stria vascularis/spiral ligament of Shaker -1 and Shaker -2 mice were at normal levels and correlated better with the rather normal morphology of the tissues than the abnormal composition of endolymph in these mutants.

Key words: adenylate cyclase; inner ear; embryologic development; postnatal maturation; $\mathrm{CBA} / \mathrm{CBA}$ mouse; Shaker -1 ; Shaker -2 .

\section{INTRODUCTION}

Based on morphological features, the stria vascularis of the cochlea and the dark cell epithelium of the vestibular system are regarded tissues involved in the formation of endolymph. The existence of two independent systems for endolymph production has, indeed, been illustrated by Kimura et al. [11] who blocked the ductus reuniens and the endolymphatic duct and sac in the guinea pig. Hydrops occurred in both the scala media and the vestibular part of the membranuus labyrinth.

During embryologic development of the inner ear the dark cell epithelium is rather mature at birth except for an increase of the number of interdigitations towards the basal membrane which occurs 1-4 DAB (days after birth) [1]. The structural maturation of the stria vascularis takes place postnatally and correlates well with the development of the specific high concentration of potassium in endolymph [2]. On the other hand, in genetic inner ear degeneration of the cochleo-saccular type ad modum Scheibe [21] the elemen- 
tal composition of endolymph was altered before morphological changes were evident in the stria vascularis of Shaker -1 and Shaker -2 mice [3].

Biochemical mechanisms involved in fluid regulation in the inner ear are not known. Previously, $\mathrm{Na}^{+} / \mathrm{K}^{+}$-activated ATPase has been linked to the development of the endolymphatic potential in the rat [12]. Another enzyme potentially involved in ion and fluid transport is adenylate cyclase. Such a role of this enzyme is established for the renal tubule, epithelia of the intestine, stomach and toad bladder [24] * but is only speculative for the inner ear. This speculation is primarily based on parallel effects of ethacrynic acid on strial adenylate cyclase and on the endolymphatic potential [25]. In this study we investigate the embryologic and early postnatal development of adenylate cyclase in the inner ear of the mouse and its possible correlation with the maturation of anatomical structures and inner ear fluids.

\section{MATERIAL AND METHODS}

The gestation period of the CBA/CBA mouse which was used in these experiments is 21 days considering the day of the vaginal plug as day 1 . The stock of Shaker -1 and Shaker -2 mice was obtained from The Jackson Laboratory, Bar Habor, Maine, in 1978.

\section{Embryologic material}

After cervical dislocation of the pregnant mouse the uteri were placed into ice-cold $0.32 \mathrm{M}$ sucrose $/ 1 \mathrm{mM}$ Tris- $\mathrm{Cl}, \mathrm{pH} 7.6$, as dissecting medium. The fetuses were removed and placed in fresh medium to avoid contamination by blood. The inner ears were dissected out with watchmaker's forceps and collected in cold dissecting medium.

\section{Postnatal material}

After decapitation the temporal bones were quickly removed and placed in ice-cold dissecting medium. Calcification of the otic capsule is in progress at birth but does not become extensive until the end of the first week. Specimens of 0-4 DAB (days after birth) were easy to dissect leaving the membranous structures rather intact. At later stages of postnatal maturation the otic capsule was brittle and could become fractured at several places during dissection. The cochlear and vestibular parts were separated. In a part of the material the otic capsule was removed from the cochlea and the tissue of the lateral wall of the scala media was dissected for separate analysis.

\section{Biochemical assays}

Tissues were carefully homogenized by hand in the dissecting medium, using glass tubes and pestles. Protein was determined spectrophotometrically [14] and approximately $20-40 \mu \mathrm{g}$ of protein were employed for each assay. To start the incubation, 30 $\mu 1$ of homogenate were added to $70 \mu 1$ of medium containing (final concentrations) 100 $\mathrm{mM}$ Tris- $\mathrm{Cl}$, $\mathrm{pH} 7.6,4 \mathrm{mM} \mathrm{MgCl}, 0.2 \mathrm{mM}$ isobutylmethylxanthine, $10 \mu \mathrm{g}$ bovine serum albumin, $2 \mathrm{mM}$ ATP and $100 \mathrm{mM}$ sucrose (from the added homogenate). An ATP-

\footnotetext{
* It should be noted that the term 'adenylate cyclase' in this context refers to the adenylate cyclasecyclic AMP system rather than the enzyme per se. Effects on adenylate cyclase are reflected in the intracellular levels of cyclic AMP. Cyclic AMP in turn may control the degree of membrane phosphorylation and thereby selective permeability.
} 
regenerating system was not necessary (see Results). Incubations were terminated with 25 $\mu 1$ of $10 \%$ trichloroacetic acid, and the protein precipitate was removed by centrifugation. The supernatant was passed over a small column of Dowex $50\left(\mathrm{H}^{+}\right)$and cyclic AMP eluted with distilled water [23]. Cyclic AMP was analyzed by radioimmunoassay (BectonDickinson, Orangeburg, N.Y.).

Analytical electron microscopy

The preparation of sections for the X-ray energy dispersive analyses and the analytical equipment has been described in detail by Wroblewski et al. [26] and Anniko and Wroblewski [3]. In brief: The inner ear region from fetuses and the temporal bones from postnatal animals were plunged after removal directly into liquid propane cooled by liquid nitrogen at $-190^{\circ} \mathrm{C}$ and thereafter stored at $-80^{\circ} \mathrm{C}$. All specimens were serial-sectioned with a cryostat to $16 \mu \mathrm{m}$ thick sections. These were lifted from the knife edge with a fine brush and transferred to a highly polished cooled pure carbon plate as a specimen holder. The specimens were freeze-dried and later coated with carbon to decrease charging of the specimens during irradiation by the electron beam. The sections were viewed in a Jeol scanning electron microscope and analyzed with an energy-dispersive spectrometer (Kevex), at $20 \mathrm{kV}$. During analysis, the cold trap and the cold finger of the instrument were in operation.

\section{RESULTS}

\section{Specimens}

The inner ear of the 13th gestational day is cystic (otocyst) with an elongation at one end which becomes the cochlear hook (Fig. 1). During dissection the otocyst epithelium

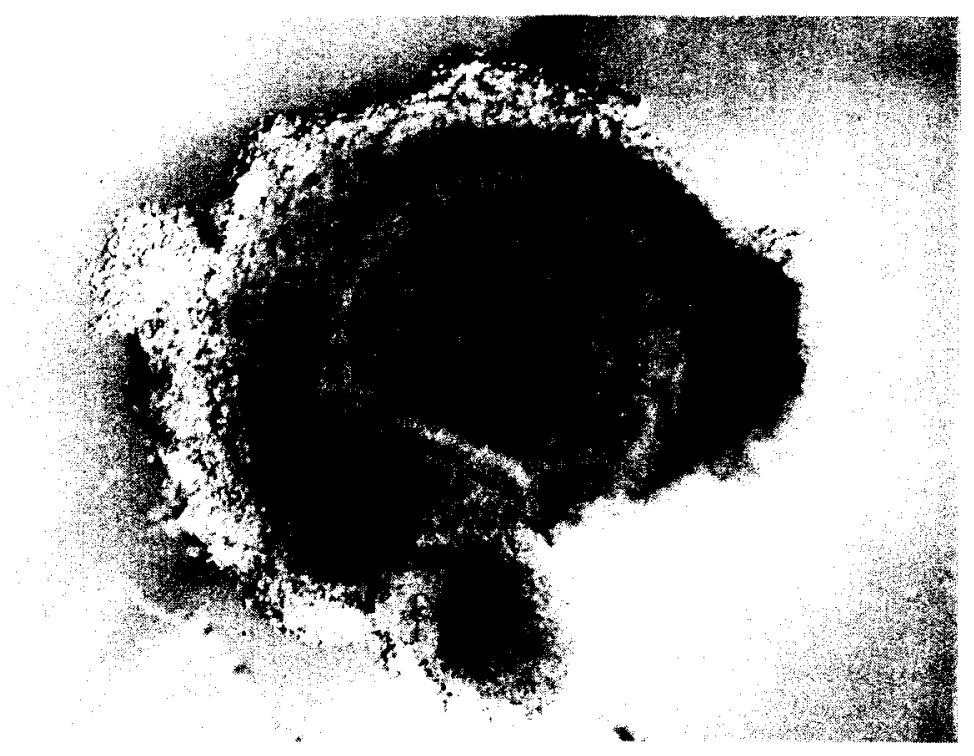

Fig. 1. The otocyst of the 13 th gestational day is removed together with adjacent mesenchyme. (Light microscopy, approximately $28 \mathrm{X}$ ). 
was freed from surrounding structures but mesenchyme adjacent to the otocyst remained included in the specimen. This adjacent mesenchyme also contained adenylate cyclase activity, but at a low level. From separate analyses of mesenchymal material it was concluded that it would not contribute more than $10 \%$ to the measured adenylate cyclase activity of an otocyst specimen.

The inner ear of the 16th gestational day has mostly ended its morphogenesis. The inner ear is surrounded by a cartilagenous capsule which makes it easy to separate the inner ear from surrounding mesenchyme. Vestibular and cochlear structures are easily identified and divided (Fig. 2). Inner ears from the 19th and 21st gestational days were treated similarly.

\section{Biochemical assays}

The assay conditions without an ATP-regenerating system are well suited for the analysis of enzymatic activities in cochlear tissues and otocysts (Fig. 3). Interference by ATPases from this material can be ruled out from the strict linearity of the assay with regard to time and protein concentration. This is further supported by comparing the enzymatic activities obtained with ATP to those obtained with AMP-PNP, an ATP analog which is not hydrolyzed by ATPases, and which we had studied earlier [5]. In parallel assays, activity of cochlear homogenates was consistently 3 to 5 times higher with ATP than with the analog, e.g. $3.30 \mathrm{pmol}$ cAMP formed $/ \mathrm{min} / \mathrm{mg}$ protein with ATP vs. 1.05 pmol with AMP-PNP. This is somewhat in contrast with Paloheimo and Thalmann [16]

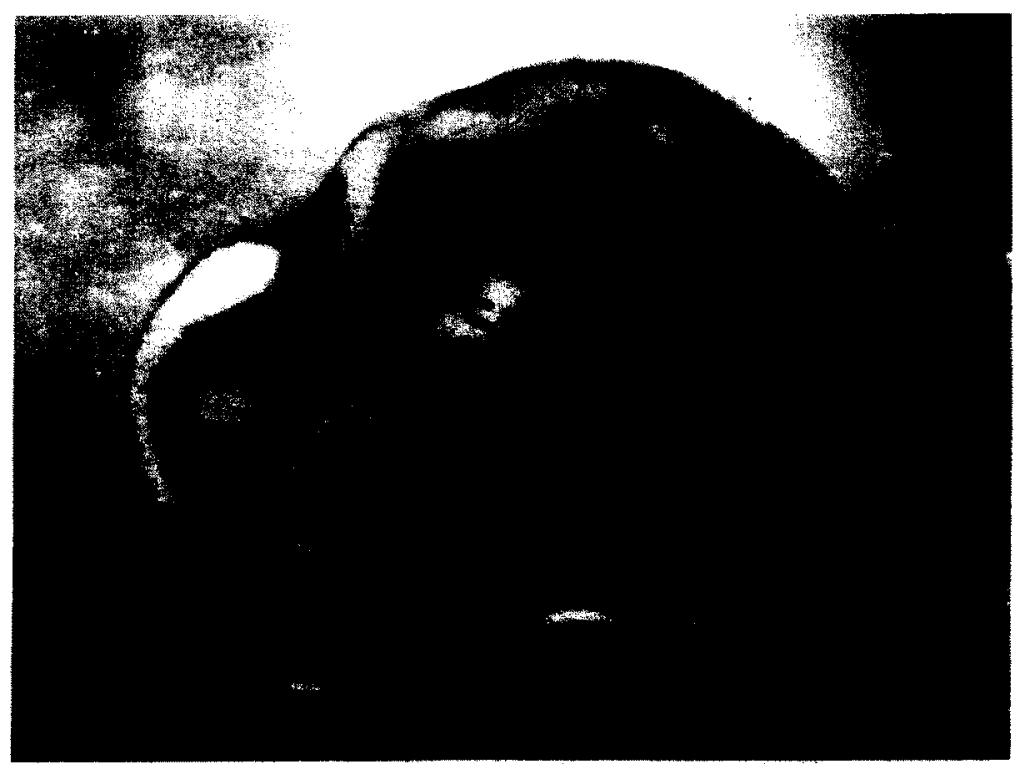

Fig. 2. Inner ear of the 16 th gestational day after excision from the fetus. The gross morphology is well developed: cristae ampullares $(*)$, utricle $(U)$, saccule $(S)$, semicircular canals (SCC) and cochlear end (CE). For biochemical analyses the inner ear was divided into a cochlear and a vestibular part as indicated by the dotted line. (Light microscopy, approximately $40 \mathrm{X}$ ). 

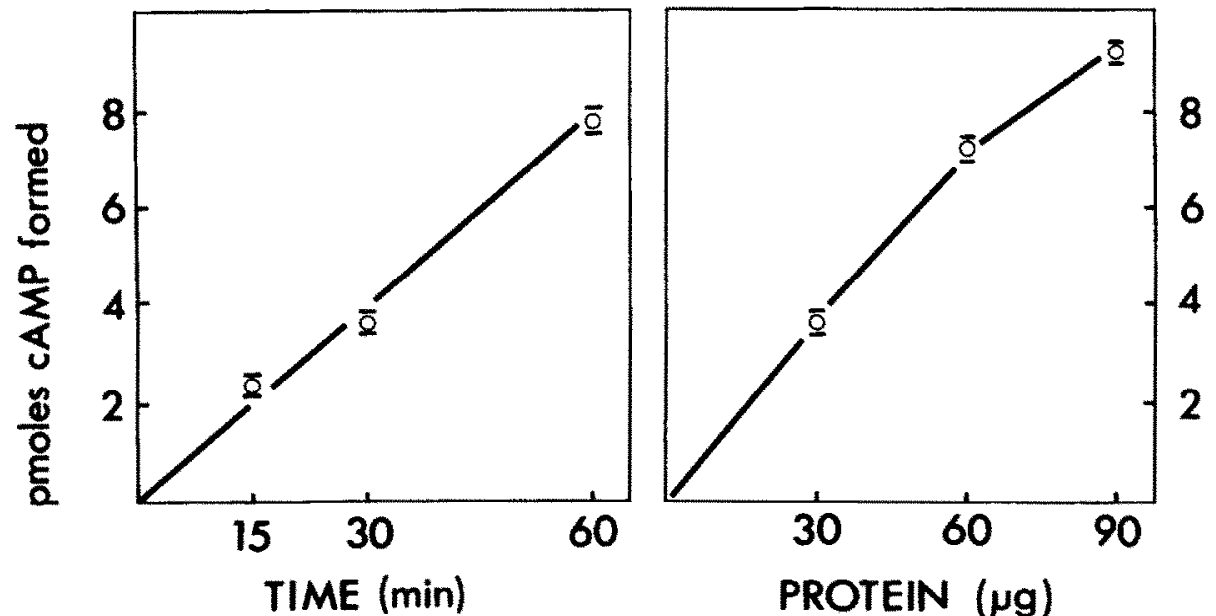

Fig. 3. Left: Time course of adenylate cyclase assay. A homogenate ( $30 \mu \mathrm{g}$ protein) of inner ears of the 16th gestational day was incubated for the times indicated as described in Materials and Methods. Right: Protein dependency of adenylate cyclase assay. Various amounts of homogenate of inner ears of the 16th gestational day were incubated for $30 \mathrm{~min}$ as described in Materials and Methods.
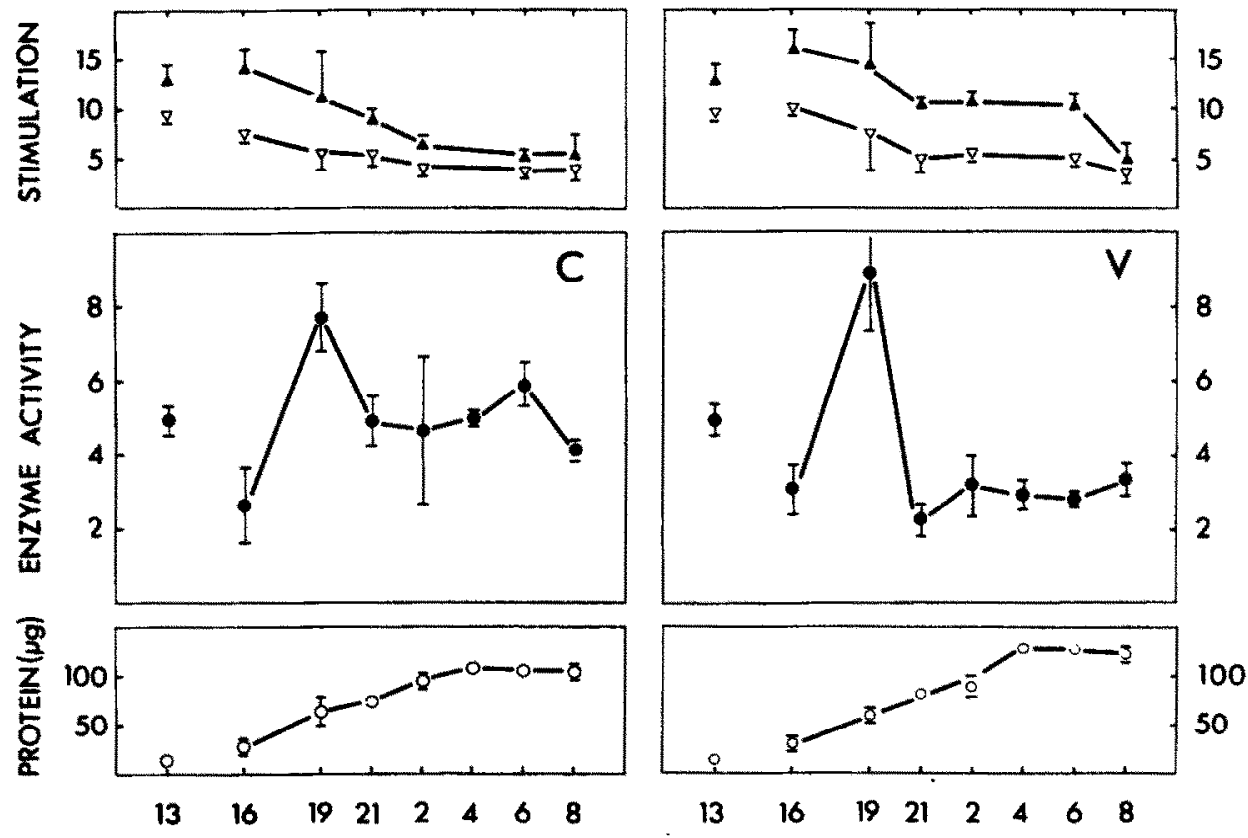

Gestational Post partum

Fig. 4. Development of the inner ear. Left panels: cochlear; right panels: vestibular part. Data for day 13 are from undivided otocysts. Lower panel: Protein content per cochlear or vestibular part of inner ear $(\mu \mathrm{g})$. Middle panel: Activity of adenylate cyclase expressed as pmoles cAMP formed $/ \mathrm{min} / \mathrm{mg}$ pro-

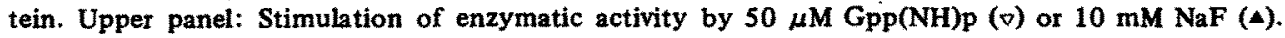
Data are means and range of two to four determinations. The differences between day 16 and 19 for both the cochlear and the vestibular part are significant at $P<0.01$. 
who found only comparable activities with the two substrates but is in good agreement with kinetic studies on the behavior of the two compounds as substrates for the adenylate cyclase reaction [15].

Both the vestibular and cochlear parts of the developing inner ear grow at a rather constant rate from the 16 th gestational day to 4 days after birth after which the protein content of the dissected specimens remained constant (Fig. 4, bottom). During this time, the specific activity (per mg protein) of adenylate cyclase increased from day 16 to 19 and remained at a rather constant lower level thereafter, with another possible increase in the cochlea only at $6 \mathrm{DAB}$ (Fig. 4, middle panel).

Stimulation by fluoride and guanylyl imidodiphosphate, $\mathrm{Gpp}(\mathrm{NH}) \mathrm{p}$, both known activators of adenylate cyclase, is evident at all times. Both agents are most effective during early development, with fluoride enhancing enzymatic activity 13- to 16-fold, Gpp(NH)p 8- to 10-fold. After birth, these levels decrease to a 3- to 5-fold stimulation.

The possibly increased activity at day 6 after birth in the cochlear preparations was further investigated in specimens containing tissues only of the lateral wall of the scala media, i.e. the stria vascularis and spiral ligament. There was a rise of activity from 2 to 6 DAB, at which day the enzymatic activity was approximately three times higher than in preparations from adult animals (Fig. 5).

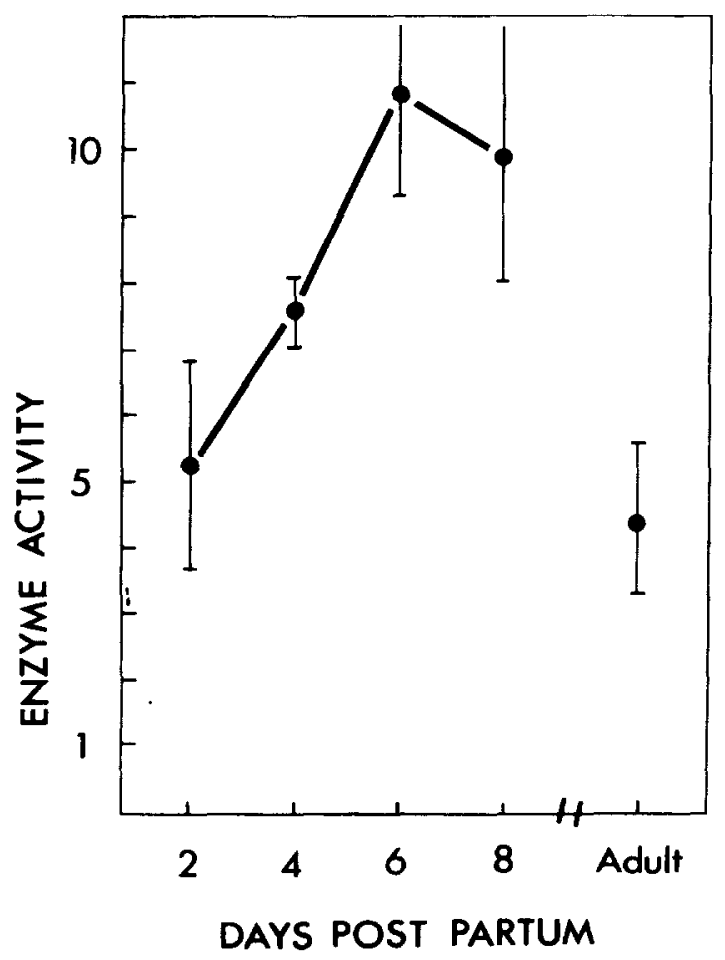

Fig. 5. Adenylate cyclase in stria vascularis and spiral ligament postpartum. Activity is given as pmol cAMP formed $/ \mathrm{min} / \mathrm{mg}$ protein. Numbers are means \pm S.D. of four to ten determinations. The difference between $6 \mathrm{DAB}$ and adult is significant at $P<0.01$. 


\section{TABLE I}

ADENYLATE CYCLASE LEVELS IN NORMAL AND MUTANT MICE

\begin{tabular}{|c|c|c|c|c|}
\hline \multirow[t]{2}{*}{ Mouse } & \multirow[t]{2}{*}{$\begin{array}{l}\text { Age } \\
\text { (weeks) }\end{array}$} & \multicolumn{3}{|c|}{$\begin{array}{l}\text { Adenylate cyclase activity } \\
\text { (pmol cAMP formed } / \mathrm{min} / \mathrm{mg} \text { protein) }\end{array}$} \\
\hline & & Mean & Range & $n *$ \\
\hline CBA & 6 & 4.3 & $3.4-6.7$ & 10 \\
\hline Shaker 1 (homozygote) & 4 & 4.9 & $3.3-6.3$ & 4 \\
\hline Shaker 1 (heterozygote) & 4 & 5.1 & $4.4-5.9$ & 2 \\
\hline Shaker 2 (homozygote) & 3 & 5.6 & $5.3-5.9$ & 2 \\
\hline
\end{tabular}

${ }^{*} n$, the number of determinations each on different pools of stria vascularis/spiral ligament from at least two animals each.

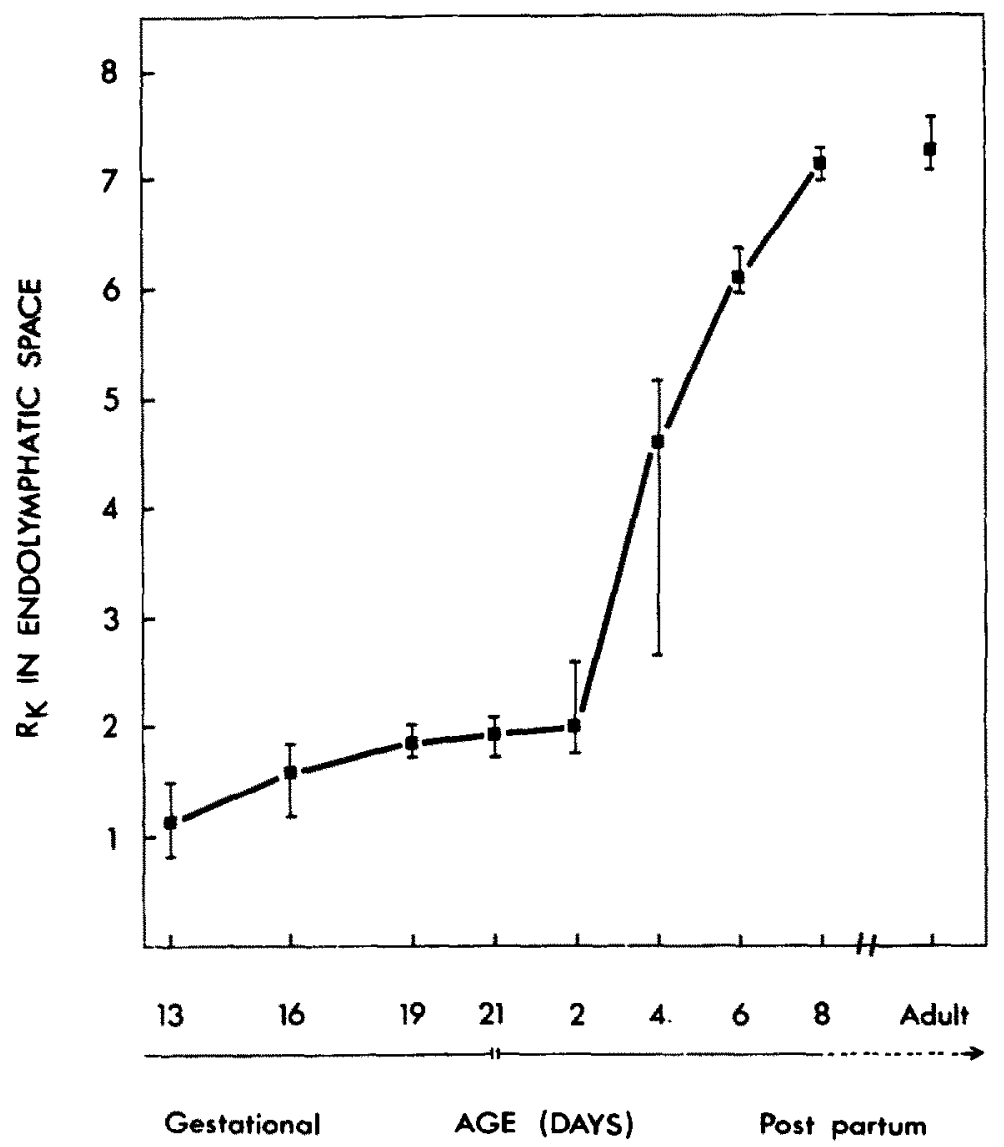

Fig. 6. Potassium concentration in the developing inner ear expressed as relative peak intensity of potassium $\left(R_{\mathrm{K}}\right)$ during embryologic and early postnatal maturation. Values are means and range from 4 inner ears each. In otocysts, analyses were performed on the lumen, from the 16 th gestational day on the scala media of the basal coil. 'Adult' is 2 months old. For further details see [4]. 

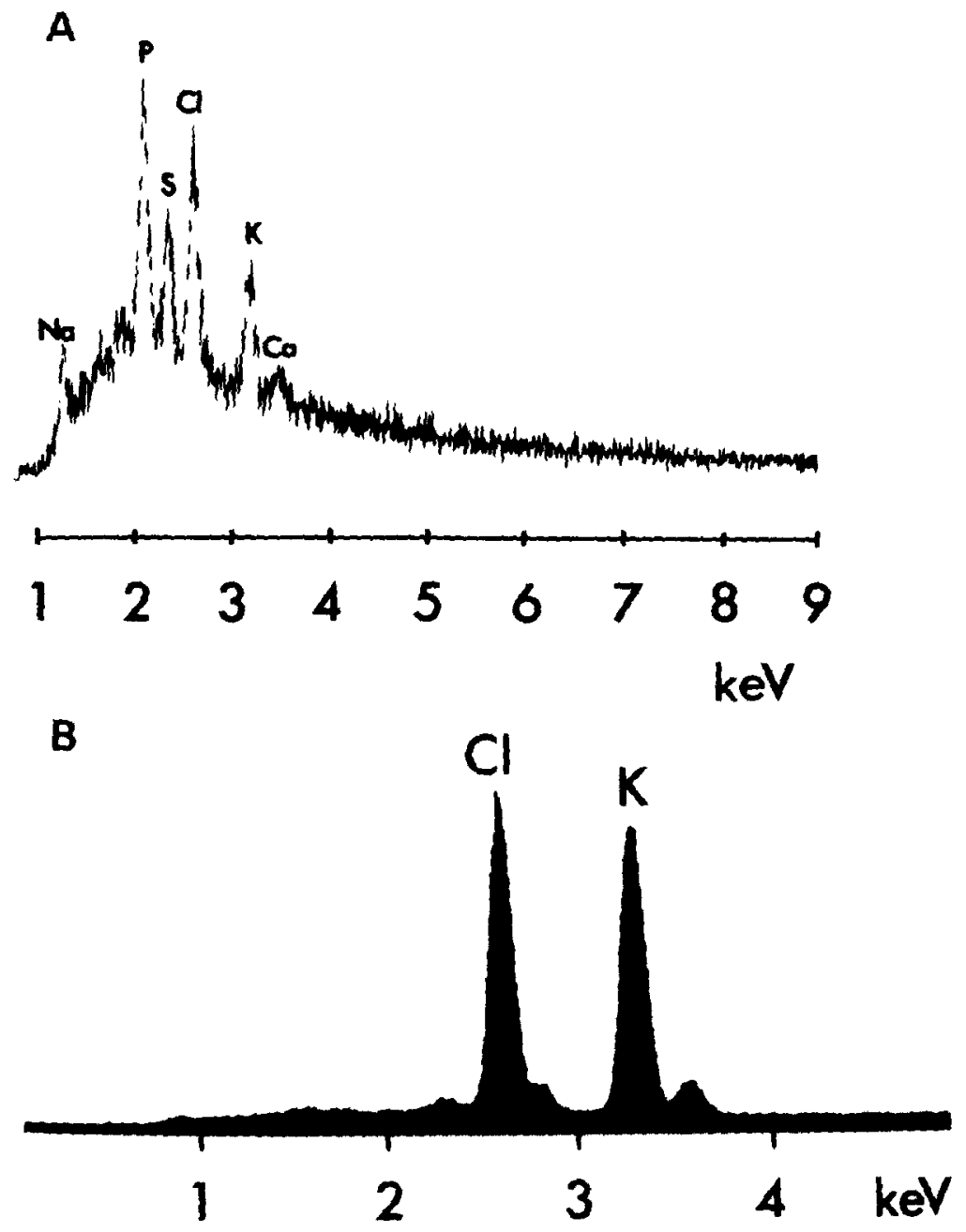

Fig. 7. Emitted energy histogram. Scala media of the basal coil. A. $4 \mathrm{DAR}$. Na, P, S, Cl, K and Ca are identified. Full scale: 500 . B. 8 DAB. Only two peaks $(C l$ and $K)$ are identified. Full scale: 2000 .

The stria vascularis (with the spiral ligament) of homozygotic Shaker -1 and Shaker -2 mutants was also investigated. Levels of adenylate cyclase were comparable to those in the adult CBA mouse and apparent heterozygotes (Table I).

$X$-ray energy dispersive analysis

The elemental composition of the content of scala media of the normal CBA/CBA mouse showed considerable changes between 4 and $8 \mathrm{DAB}$. Concentrations of sodium, sulphur and phosphorus decreased while the peaks for chlorine and potassium increased (Figs. 6, 7A and B). Compared with analyses of adult inner ears the elemental composition of the scala media had a mature appearance $8 \mathrm{DAB}$ (Fig. 7B). 


\section{DISCUSSION}

Activity of adenylate cyclase in the cell is regulated by complex mechanisms and neither basal nor fluoride- or Gpp(NH)p-stimulated levels of adenylate cyclase in vitro may accurately reflect the enzymatic activity in vivo. The membrane-bound enzyme consists of at least three components: a catalytic unit, a hormone receptor and a regulatory site probably involved in the coupling of the first two $[17,20]$.

Fluoride and guanyl nucleotide interact with the regulatory component of the enzyme complex and the development of this activity appears to vary in different tissues. In the rat, for instance, fluoride stimulation of the enzyme in liver is high at birth but low in brain where the response increases postnatally [19]. In this study, both cochlear and vestibular adenylate cyclase respond similarly to these agents. Highest stimulation is seen during early development followed by a period of decreasing response which seems to stabilize after birth. The relation of this in vitro behavior to enzymatic activity in vivo remains unclear.

Hormonal responsiveness which may be decisive for in vivo activity can develop independently of the basal enzyme levels [19]. It usually can only be demonstrated in membrane preparations which were not used in this study. Moreover, hormones acting on strial adenylate cyclase are yet unknown, although Zenner and Zenner [27] reported stimulation of a 'cochlear' adenylate cyclase by vasopressin and the $\beta$-adrenergic agonist, isoproterenol.

Despite such limitations of in vitro/in vivo comparisons our measurements of basal enzyme levels point out interesting correlations with the development of tissues and fluids. Adenylate cyclase activity in the developing inner ear of the mouse shows two significant periods of fluctuation: from the 16th to the 19th gestational day in both the cochlear and vestibular parts of the labyrinth, and from birth to day 6 after birth in the lateral wall tissues of the cochlea. From the 16 th to the 19 th gestational day the specific activity of the enzyme (i.e. activity per mg protein) increases about 3 -fold while the total activity per inner ear anlage increases about 7-fold due to the growth of the labyrinth $(0.07 \pm 0.03 \mathrm{~S} . \mathrm{D}$. pmol cAMP formed $/ \mathrm{min}$ per anlage at 16 th day; $0.49 \pm 0.09 \mathrm{pmol}$ at 19th day). Thereafter the subsequent growth proceeds without concomitant increases of total enzymatic activity $(0.43 \pm 0.26 \mathrm{pmol}$ at $2 \mathrm{DAB})$ so that the specific activity is lowered.

The period between the 16 th and 19th gestational days is anatomically characterized as an active period of histogenesis and cytodifferentiation. The dark cell epithelium reaches an electron optically mature configuration except for a limited number of cell projections towards the basal membrane [1]. The stria vascularis starts to differentiate on the 17th day of gestation, i.e. the anatomical location can be distinguished from surrounding structures. The epithelium consists of cuboidal cells which histologically stain more intensely than cells in those adjacent parts of the lateral wall of the scala media that do not develop into the stria vascularis [22]. It is thus possible that changes in the concentrations of adenylate cyclase are related to morphological and biochemical differentiation of the secretory epithelia.

After birth, adenylate cyclase activity remains rather constant in the vestibular system while the enzyme activity increases in the cochlea, clearly seen in the preparation of stria 
vascularis/spiral ligament. Morphologically this period is characterized by a rapid maturation of the stria vascularis [2]. At birth it consists of one cell layer with cuboidal or slightly pillar-shaped cells. During the following 2-4 days the marginal cells show projections basalwards and the intermediate and basal cells become included in the stria vascularis and clearly separated from the spiral ligament.

During this period of postnatal development the elemental composition in scala media changes to adult values. The concentration of potassium increases to mature levels from 4 to $8 \mathrm{DAB}$, following closely the rise of adenylate cyclase activity. Sodium levels had decreased already on the 2 nd -4 th $D A B$ while a reduction of phosphorus, sulphur and calcium concentration did not occur until the 6 th -8 th DAB [4].

While the foregoing results support a link between adenylate cyclase and the control of inner ear fluids, two findings seem to disagree with such a hypothesis: enzyme levels in the postnatal vestibular system and in the Shaker mutants. As we will discuss, these discrepancies need not contradict the proposed role for adenylate cyclase but they may indicate limits of our assay techniques which are based on the analysis of anatomically diverse tissue preparations. They may also point to inherently complex mechanisms of labyrinthine fluid control.

Endolymph is formed in both the vestibular and cochlear parts of the inner ear $[9,10$, 11], yet we find increased adenylate cyclase only in the postnatal cochlea. This can be due to differences in biochemical mechanisms operating in the dark cell epithelium and the stria vascularis. In experimental pathology of the inner ear, these two tissues react differently, e.g. when exposed to ototoxic diuretics $[18,6,8]$. In the stria vascularis a marked oedema occurs between the marginal and intermediate cells, as well as intracellular changes of ultrastructure and a considerable stretching of marginal cells. Often the intermediate cells are difficult to identify. In contrast, morphological changes in the dark cells around the vestibular organs following ethacrynic acid administration have been reported to be absent. However, it has to be noted that according to the work by Kusakari and Thalmann [13] the biochemical results of ethacrynic acid intoxication are much the same in the vestibular labyrinth as in the cochlea.

An important feature is that the elemental composition of vestibular endolymph is not mature at birth. According to preliminary data (Anniko, in preparation) the relative peak intensity of potassium is at this stage of development higher in vestibular than in cochlear endolymph but the general composition has not reached mature conditions in none of these two compartments. Thus, it is not unlikely that the increasing relative peak intensity of potassium in vestibular endolymph can be correlated to the high adenylate cyclase activity on the 19 th gestational day.

The morphological observations following ethacrynic acid intoxication together with our findings of an unchanged level of adenylate cyclase postnatally in the vestibular part of the inner ear may indicate that other enzyme systems than adenylate cyclase contribute to the formation of vestibular endolymph. However, if crucial changes of adenylate cyclase activities were confined to anatomical substructures of the vestibular system such as the dark cell epithelium they may not become evident in dissected specimens which contain the entire tissue with its diversified structures.

Another discrepancy seems to exist in Shaker -1 and Shaker -2 mice. At approximately one month of age, the relative concentrations of potassium and chlorine in scala 
media were lower than in normal animals and sodium, phosphorus, sulphur and calcium were detected as in immature endolymph [3]. Ultrastructural changes in stria vascularis are not yet evident in the Shaker -1 mouse at this age and only minor general changes were seen in the stria vascularis of the Shaker -2 animals. The normal adenylate cyclase activity in stria vascularis/spiral ligament of these mutants correlates better with the morphology of the tissues than the pathology of the fluids. It could support the idea that structures other than the stria vascularis must also be involved in the maintenance of endolymph. On the other hand again, if adenylate cyclase in only a certain cell population (e.g. the marginal cells of the stria vascularis) is linked to the control of endolymph, the dissected preparation is likely to be inadequate for the detection of localized changes. The investigation of these problems by cytochemical procedures seems indicated. However, we believe that the sequence in the changes of adenylate cyclase activity and elemental composition is of outermost importance. The findings of a normal level of adenylate cyclase activity in the 1 month old Shaker mice does not imply the assumption that the postnatal rise in activity occurred also in these animals at the usual time (which was not investigated). The Shaker animals might be compared more accurately with normal animals at birth concerning both the elemental composition of the endolymphatic space and the adenylate cyclase activity. It therefore seems likely that the normal postnatal increase of enzyme activity has not occurred. The short period of increase of adenylate cyclase activity in normal animals seems to be concerned with the production of the mature composition of endolymph.

In a developmental study on $\mathrm{Na}^{+}, \mathrm{K}^{+}$-ATPase, Kuijpers [12] showed that a rise of the activity of this enzyme occurred approximately during the period when the endolymphatic potential increases to its mature values. The ionic composition of endolymph, however, had already reached adult values prior to this period [7]. It is tempting to speculate that adenylate cyclase is an enzyme involved in the early control of the ionic composition of endolymph. The correlations established here tend to support such a hypothesis while the discrepancies discussed above would caution against simply equating strial adenylate cyclase with this role. It is more likely that complex mechanisms operate of which adenylate cyclase may be an important factor.

\section{ACKNOWLEDGEMENTS}

Supported by grants from Karolinska Institutet, The Swedish Medical Research Council (12X-720) and The Torsten and Ragnar Söderberg Foundation (M. Anniko). Also supported by research grants NS-12881, Program Project Grant NS-5785, and a Senior International Fellowship (F06-TW00390) of the Fogarty International Center, National Institutes of Health (J. Schacht).

\section{REFERENCES}

[1] Anniko, M. (1980): Embryologic development in vivo and in vitro of the dark cell region of the mammalian crista ampullaris. Acta Otolaryngol. 90, 106-114.

[2] Anniko, M. and Nordemar, H. (1981): Embryogenesis of the inner ear. IV. Early post natal maturation of the vestibular dark cells and the stria vascularis in the cochlea of the mammalian inner 
ear in correlation with the elemental composition of endolymph. Arch. Oto-Rhino-Laryngol., in press.

[3] Anniko, M. and Wroblewski, R. (1980): Deterioration of the elemental composition of endolymph in genetic inner ear disease. Arch. Oto-Rhino-Laryngol. 228, 171-186.

[4] Anniko, M. and Wroblewski, R. (1981): Elemental composition of the developing inner ear. Ann. Otol. Rhinol. Laryngol., in press.

[5] Bagger-Sjöbäck, D., Filipek, C.S. and Schacht, J. (1980): Characteristics and drug responses of cochlear and vestibular adenylate cyclase. Arch. Oto-Rhino-Laryngol. 228, 217-222.

[6] Bosher, S.K., Smith, C. and Warren, R.L. (1973): The effects of ethacrynic acid upon the cochlear endolymph and stria vascularis. Acta Otolaryngol. 75, 184-191.

[7] Bosher, S.K. (1972): Neonatal changes in the endolymph and their possible relationship to perinatal deafness. Acta Otolaryngol. 73, 203-211.

[8] Brummett, R., Smith, C.A., Keny, Y., Cameron, S. and Richter, R. (1977): The delayed effects of ethacrynic acid on the stria vascularis of the guinea pig. Acta Otolaryngol. 83, 98-112.

[9] Dohlman, G.F. (1964): Secretion and absorption of endolymph. Ann. Otol. Rhinol. Laryngol. 73, 708-723.

[10] Dohiman, G.F. (1965): The mechanics of secretion and absorption of endolymph in the vestibular apparatus. Acta Otolaryngol. 59, 275-288.

[11] Kimura, R.S., Schuknecht, H.F., Ota, C.Y. and Jones, D.B. (1980): Obliteration of the ductus reuniens. Acta Otolaryngol. 89, 295-303.

[12] Kuijpers, W. (1974): Na-K-ATPase activity in the cochlea of the rat during development. Acta Otolaryngol. 78, 341-344.

[13] Kusakari, J. and Thalmann, R. (1976): Effects of anoxia and ethacrynic acid upon ampullar endolymphatic potential and upon high energy phosphates in ampullar wall. Laryngoscope 76 , $132-147$.

[14] Lowry, O.H., Rosebrough, N.J., Farr, A.L. and Randall, R.J. (1951): Protein measurement with the Folin phenol reagent. J. Biol. Chem. 193, 265-275.

[15] Maguire, M.E. and Gilman, A.G. (1974): Adenylate cyclase assay with adenylyl imidodiphosphate and product detection by competitive protein binding. Biochim. Biophys. Acta 358, 154160.

[16] Paloheimo, S. and Thalmann, R. (1977): Influence of 'loop' diuretics upon $\mathrm{Na}^{+} \mathrm{K}^{+}-\mathrm{ATPase}$ and adenylate cyclase of the stria vascularis. Arch. Oto-Rhino-Laryngol. 217, 347-359.

[17) Pfeuffer, T. (1977): GTP-binding proteins in membranes and the control of adenylate cyclase activity. J. Biol. Chem. 252, 7224-7234.

[18] Quick, C.A. and Duvall, A.J. (1970): Early changes in the cochlear duct from ethacrynic acid: an electron microscopic evaluation. Laryngoscope 80, 954-965.

[19] Robison, G.A., Schmidt, M.J. and Sutherland, E.W. (1970): On the development and properties of the brain adenyl cyclase system. Adv. Biochem. Psychopharmacol. 3, 11-30.

[20] Ross, E.M. and Gilman, A.G. (1977): Resolution of some components of adenylate cyclase necessary for catalytic activity. J. Biol. Chem. 252, 6966-6969.

[21] Scheibe, A. (1891-1892): Ein Fall von Taubstummheit mit Acusticusatrophie und Bildungsanomalien in häutigen Labyrinth beiderseits. Z. Ohrenheilk. 22, $11-24$.

[22] Sher, A.E. (1971): The embryonic and post natal development of the inner ear of the mouse. Acta Otolaryngol. Suppl. 285, 1-77.

[23] Steiner, A.L. (1974): Assay of cyclic nucleotides by radioimmunoassay methods. In: Methods in Enzymology, Vol. 38, pp. 96-105. Editors: J.G. Harman and B.W. O'Malley. Academic Press, New York.

[24] Strewler, G.J. and Orloff, J. (1977): Role of cyclic nucleotide in the transport of water and electrolytes. Adv. Cycl. Nucl. Res. 8, 311-363.

[25] Thalmann, R., Ise, I., Bohne, B.A. and Thalmann, I. (1977): Actions of loop diuretics and mercurials upon the cochlea. Acta Otolaryngol. 83, $221-232$.

[26] Wroblewski, R., Roomans, G.M., Jansson, E. and Edström, L. (1978): Electron probe X-ray microanalysis of human muscle biopsies. Histochemistry 55, 281-292.

[27] Zenner, H.-P. and Zenner, B. (1979): Vasopressin and isoproterenol activate adenylate cyclase in the guinea pig inner ear. Arch. Oto-Rhino-Laryngol. 222, 275-283. 